\title{
A ÓPERA de PEQuim em “O DRAGÃO DE FOGO"
}

RESUMO

Artigo reflexão sobre o processo de ressignificação da estrutura e de elementos de composição da ópera de Pequim no espetáculo "O dragão de fogo" de Cássio Pires e direção de Marcelo Lazzaratto.

Palavras-chave:

Ópera de Pequim; Gongfu; "O dragão de fogo" 


\section{A Ópera de Pequim em "0 dragão de fogo"}

Luciana Mizutani

Marcelo Lazzaratio

Luciana Mizutani - Atriz e preparadora corporal, formada em Artes Cênicas pela Unicamp. É mestranda em Artes da Cena pelo Programa de Pós-Graduação do Instituto de Artes da Unicamp

lumizu@gmail.com

Prof Dr. Marcelo Lazzaratto - É ator, diretor, pesquisador teatral e Doutor em Artes. Leciona no Departamento de Artes Cênicas da Universidade Estadual de Campinas e é diretor artístico da Cia. Elevador de Teatro Panorâmico.

mailto:marevi@uol.com.br

${ }^{1} \mathrm{O}$ gong fu é um termo genérico para se designar as artes marciais chinesas. Segundo Andraus, o "termo pode ser traduzido, grosso modo, como "habilidade acumulada”, ficando implícita a ideia de que requer muitos anos de treinamento" (ANDRAUS, 2004, p37).

\section{Introdução}

O projeto surgiu do desejo de Eduardo Okamoto de montar um espetáculo de teatro infantil. Sem subestimar o entendimento e a experiência estética do pequeno espectador, a escolha foi o texto "O dragão de fogo" de Cássio Pires, com quem Okamoto já havia trabalhado nos projetos de "OE" e "Chuva Pasmada", respectivamente com direções de Marcio Aurélio e Marcelo Lazzaratto.

Pires partiu de estudos e narrativas asiáticas para contar a história, situada em um cantinho da China, de um menino desenhista escolhido pelo destino para enfrentar o dragão de fogo. Com a ideia de inspirar-se na estética da ópera de Pequim, Okamoto propõe o projeto ao diretor Marcelo Lazzaratto e, juntos, montam a equipe para esse trabalho. Assim, pelo conhecimento marcial e luta cênica, eu, Luciana Mizutani, passei a integrar o elenco, assinar o treinamento em gong $f u^{1}$ e a direção de movimento do espetáculo.

A SIM! Cultura, produtora da cidade de Campinas, sediada no distrito de Barão Geraldo, realiza a produção inédita do texto que teve financiamento do Proac, Programa de Ação Cultural do Governo de Estado de São Paulo.

Este artigo é uma coautoria entre Luciana Mizutani e o diretor do espetáculo, Marcelo Lazzaratto, que procura reconhecer algumas das estruturas da ópera de Pequim e os processos de adaptação e ressignificação para a montagem da peça "O dragão de fogo". 


\section{A Ópera de Pequim}

A ópera chinesa ou ópera de Pequim são as traduções ocidentais para o teatro oriental conhecido como jīngjù ${ }^{2}$ na China ou o guójù ${ }^{3}$ em Taiwan. Trata-se de uma forma espetacular que engloba teatro, poesia, música, canto, dança, acrobacia e artes marciais.

Segundo Berthold (2001), com origem nas peças musicais da era Ming (1368 a 1644), a ópera mantém muitas de suas características: os figurinos da época de ouro do período, o palco destituído de cenários, a precisão de linguagem gestual, as longas mangas e o controle artístico do corpo.

Seu repertório é dividido entre peças civis e marciais. As civis têm enfoque na narração, e em geral são histórias de amor. As marciais têm enfoque corporal tanto nas acrobacias quanto nas artes marciais.

Marcado por forte estilização, a ópera de Pequim possui quatro grandes grupos de tipos de personagens: sheng, dan, jing e chou. O tipo sheng são as personagens masculinas, que se dividem entre velho, jovem e marcial. Dan são as personagens femininas que, até 1870 , eram unicamente interpretadas por homens. A categoria dan é dividida em velhas, marciais, jovens guerreiras, mulheres virtuosas da elite e jovens solteiras. Os jing são os caras pintadas, podem representar uma variedade de papéis masculinos como generais, personagens fantásticos ou zoomórficos. As cores de suas maquiagens determinam o caráter da personagem: a cor vermelha indica lealdade, coragem, heroísmo; o branco uma

\footnotetext{
${ }^{2}$ Faz referência a cidade Jing onde a ópera se origina. Tradução: Teatro nacional

Um dos precursores da ópera de Pequim no ocidente, ganha visibilidade após B. Brecht assisti-lo e descrever suas impressões no ensaio em "On Chinese Acting” (BRECHT, 1936)

Wu Hsing-kuo foi uma das referências para a montagem do espetáculo, Okamoto entrou em contato com seu trabalho no Festival de Edimburgo em 2011. Ator e diretor que teve como projeto revitalizar a ópera de Pequim, $\mathrm{Wu}$ realizou adaptações de clássicos shakesperianos, dentre eles "Kingdon of desire" ("Macbeth") e "A tragédia do Príncipe Zidan" (Hamlet) onde faz uso mais tradicional da linguagem; e em "Rei Lear", em um solo em que realizava todos os papéis, já dialogando com elementos da contemporaneidade.
}

personagem má, ardilosa ou hipócrita; o preto indica integridade; o verde indica impulsividade e violência. São subdivididos com enfoque em canto e gestualidade ou marcialidade e acrobacias. As personagens chou são os palhaços ou bobos, e se dividem em civil ou marcial. São caracterizados por sua maquiagem com partes brancas sem desenhos. Cada subdivisão possui traços específicos de atuação, movimentação, entonação de voz, canto, figurino e maquiagem. Seus atores em processo de formação, o que pode levar de 8 a 10 anos antes que possam pisar nos palcos, são escolhidos pelos seus atributos e se especializam em um dos tipos de personagem ou na parte musical. O lendário ator Mei Lanfang ${ }^{4}$ era famoso por seus papéis como qingyi, papel feminino com ênfase no canto que representa uma mulher virtuosa, heroína, boa mãe ou esposa. $\mathrm{E}$ o ator taiwanês de ópera Wu Hsing-kuo é especializado em wu sheng personagens masculinos marciais.

O público familiarizado reconhece as personagens, tanto por serem conhecedores das fábulas, baseadas em romances históricos ou histórias tradicionais, como pelo código de cores e tipos de vestimentas como descrevem Souto e Monteiro:

No palco, as encenações revestem-se de espetacularidade e exuberância. Imperadores, concubinas e guerreiros, entre outras personagens, narram feitos históricos e lendas populares reproduzindo valores éticos e morais da comunidade de origem. Assim que um ator entra em cena, o público, familiarizado com as histórias representadas, reconhece facilmente a personagem pelo seu traje e pintura facial (maquiagem), cujas cores e desenhos refletem simbologias, significados, e estão sujeitos a códigos visuais. Estes códigos indicam ao público qual o estatuto social e o carácter da personagem representada. (SOUTO, MONTEIRO, 2016, p. 36) 
Uma arte tradicional com centenas de anos fabricada por artistas e seu público durante gerações é permeada por outras tradições de seu povo. É, por exemplo, possível reconhecer similaridades entre as cenas acrobáticas da ópera de Pequim e o circo imperial da China, ou entre as apresentações de artes marciais chinesas e as lutas cênicas da ópera, ou ainda entre os enredos das peças e o gênero wuxia $a^{6}$.

Hunt (2003) faz uma análise performática das artes marciais em seu livro "Kung fu cult masters" e aponta sua associação na tradição da Dança do Leão e da ópera de Pequim. Afirma ainda que a ópera está "costurada no mítico-histórico tecido do gênero wuxia". O wuxia é um gênero literário que versa sobre as heroicas aventuras de espadachins, repleto de objetos mágicos e elementos fantásticos.

Conhecido no ocidente pela recente retomada da produção do gênero na indústria cinematográfica de Hong Kong, os filmes "O tigre e o dragão", de Ang Lee, "O clã das adagas voadoras" e o "Herói", ambos de Zhang Yimou, fazem parte desse gênero com roteiros cheios de reviravoltas e de elementos fantásticos. Nesses filmes, segundo Chute (2003), normalmente acompanhamos a história de um herói que é prodígio nas artes marciais com ênfase em sua coragem ao usá-la para um determinado fim.

A intrincada relação entre essas artes faz com que a ópera de Pequim seja parte da formação de artistas que, por vezes, acabam migrando para outras áreas. Antes de se tornar diretor e coreógrafo, Yuen $\mathrm{Wo}_{\text {- }}$ ping $^{7}$ se forma em uma escola de ópera. $\mathrm{O}$ trio Jackie Chan, Yuen Biao e Sammo Hung estudaram juntos na escola de ópera e hoje são artistas marciais, atores, diretores e coreógrafos de filmes de ação.

A trilha sonora da ópera é feita ao vivo e tem como instrumento característico o jinhu, um violino com apenas duas cordas. Outros instrumentos de corda e percussão completam a sonoridade da ópera. As músicas funcionam como trilha, em consonância com a cena dando o clima. A sonoplastia, geralmente realizada pela percussão, acentua os finais de movimento, antecedendo posturas estáticas ou ainda pontuando golpes nas peças com enfoque marcial.

\footnotetext{
2 Tradução: Herói marcial

${ }^{7}$ Coreógrafo de grandes produções de Hollywood e da indústria de Hong Kong. Citamos a trilogia "Matrix", "O tigre e o dragão" e a série de filmes "Kill Bill”.
}

\section{O dragão de fogo}

A peça é contada por uma borboleta que narra a história de um menino desenhista de 7 anos, cuja aldeia é atacada por um dragão de fogo que acaba de acordar de seu sono de séculos. Partindo do princípio de que todos devem estar prontos, existe uma tradição dessa comunidade que estipula a realização de um sorteio para nomear quem enfrentará o dragão. O menino, Shun Li, é escolhido pelo destino para confrontar o dragão. Chegando à caverna do dragão, este lhe propõe um trato: se o menino conseguir realizar as três tarefas propostas, Shun Li e a sua aldeia serão deixados em paz, no entanto se o menino falhar em uma única delas, o dragão transformará todos em churrasco. $\mathrm{O}$ dragão indaga a Shun Li: qual é a coisa mais útil do mundo? A que o menino responde: $\mathrm{O}$ papel. Partindo da resposta do menino, as provas do dragão são vinculadas ao uso do papel. Nessa empreitada Shun Li conta com a ajuda de um aliado, um rato que vive na caverna do dragão. Com o auxílio deste, Shun li tem a incumbência de embrulhar fogo em papel, trazer o vento feito pelo papel e trazer a coisa mais forte e poderosa do mundo embrulhada em um papel. Shun Li consegue cumprir as tarefas e salvar a si, seu novo amigo rato e seu povo através de seus desenhos. Na primeira, Shun Li e o rato constroem uma lanterna chinesa, na segunda, inspirado na borboleta, ele faz um leque de papel. $\mathrm{Na}$ terceira, acreditando ter sido derrotado, entrega os desenhos que fez das pessoas que ama para que o dragão os guarde, para que sejam testemunha da existência de si e dos seus. O dragão reconhece nos desenhos a coisa mais forte e poderosa do mundo, o amor. Enfim, Shun Li pode retornar para casa e sua aldeia pode voltar a renascer. Contudo resta no ar a sombra de um dragão que um dia retornará e a certeza de que todos devem estar prontos para ele.

A ideia de se inspirar ou mesmo transpor elementos estéticos da ópera parece se encaixar perfeitamente com a fábula. Trata-se afinal de um conto chinês com personagens zoomórficos, assim como encontramos nas histórias da famosa personagem da ópera de Pequim, o Sun Wukong, ou o rei macaco. No entanto, as partituras de movimento como montar em um cavalo, desviar flechas, costurar ou entrar em um barco seriam de pouco uso e tampouco os figurinos, adereços, os significados das cores das maquiagens, familiares ao público da ópera, seriam 
entendidos pelo público brasileiro. Então, como repensar a ópera de Pequim no Brasil? Como proporcionar uma experiência estética análoga sem que o público tenha conhecimento da linguagem codificada e com apenas três atores?

\section{O Desenho de Shun Li}

Shun Li é apresentado ao público pelos seus desenhos e é sempre pelas relações com o desenho e com o papel que ele consegue vencer aquilo que não pode ser destruído, o dragão de fogo. Se pensarmos que a ação de desenhar constrói a história, a mesma importância deve ser aferida a sua solução cênica diante da estética da peça. Dessa forma, o conceito central da encenação é a transformação do desenho do papel para a tridimensionalidade do palco. $\mathrm{Na}$ ópera não se procura produzir uma ilusão realista, as personagens fantásticas, por exemplo, usam gestos codificados e têm adereços que remetem à sua origem. Se tomarmos como exemplo o peixe-espada e a tartaruga que são vencidos pelo rei macaco, vemos mais as figuras humanas em atitude estilizada do que uma imitação dos animais, embora estejam vestidos em suas cores e tenham gestualidade que remeta a eles. Se o cerne não for o de ilustrar as ações e as personagens, qual seria o ponto de partida para a construção dessa ação? O processo de formação dos artistas da ópera, devido à exigência da linguagem e das histórias contadas perpassa as artes marciais, especificamente o gong fu. Assim, esse parecia um campo adequado de início.

Os encontros se iniciaram, em outubro de 2016, com treinamentos de gong fu shen she chuen ${ }^{8}$ com enfoque nas posturas básicas de braços e de pernas. Também foram realizados os treinamentos de caminhadas, chutes e posicionamentos básicos da ópera de Pequim que se tornaram aquecimento para o espetáculo.

\footnotetext{
${ }^{8}$ Tradução: Punho da serpente sagrada. Estilo praticado pela atriz, designer de movimento e preparadora marcial da peça, Luciana Mizutani.

${ }^{9}$ Formas são sequências de movimentos que o praticante realiza sozinho. (ANDRAUS, 2012, p. 64)
}

Tratando-se de um menino e não de uma figura fantástica, a direção optou por um menor nível de estilização para Shun Li, interpretado pelo ator Eduardo Okamoto. Mas a problemática residia em como o menino desenharia. Como realizar esses desenhos em cena? Movimentos de gong fu com tinta e enormes papéis, pincéis e lápis? Projeções? Ou tentar criar corporalmente os desenhos? Este último parecia mais adequado ao minimalismo de adereços e cenários que se pretendia. Então, partimos dos movimentos sinuosos da serpente do gong fu shen she chuen. Os golpes, defesas e envolvimentos foram ampliados e transformados em longos traços que criavam a impressão de desenhos no ar, e os movimentos de ataque, análogos ao bote, convertidos em arremessos de tinta. Muitas artes marciais, para organizar o treinamento de uma série de técnicas de um mesmo conjunto, desenvolveram as formas ${ }^{9}$, conhecidas como katis no gong fu ou katás no karatê. Trata-se de uma partitura de técnicas, muito utilizada para estudo e transmissão de conhecimentos marciais. Durante as formas individuais, as técnicas são realizadas em inimigo(s) imaginário(s), onde o foco visual do artista marcial se volta para o local onde seu golpe/defesa/técnica se direciona ou para onde o seu "inimigo" se encontra. Porém, ao desenhar, olhamos para a imagem que se forma e não para lápis ou o pincel. Assim o foco deveria ser diferente do proposto nas formas de gong fu. Shun $\mathrm{Li}$ ao traçar, deveria "atrasar" o olhar em relação ao movimento e observar seu próprio desenho. Essa mudança sutil fez uma grande mudança no processo de significação, descortinando o desenho para o público.

Outras adaptações de movimentos e golpes surgiram por esse mesmo processo de ressignificação, por exemplo, um movimento chamado de passo do bêbado que tem um tempo sincopado aparentando desequilíbrio, usado para derrubar o adversário, foi repensado para demonstrar o cansaço de dois camponeses ao carregar pesadas sacas de arroz.

Mas como pensar nisso nas personagens que deveriam ser mais estilizadas como as personagens animais? Tratando-se de uma linguagem codificada, não encontramos as personagens do conto na ópera, seria necessário então que a corporeidade dessas personagens e a codificação de seus movimentos fossem criadas. 
$\underline{\text { O rato }}$

No caso do rato, a orientação da direção era de que a personagem, aliado de Shun $\mathrm{Li}$, não fosse tivesse todas as suas ações partituradas. A personagem é um aliado pícaro, divertido e empático. Parecia possuir características análogas às do brincalhão rei macaco da ópera. O ator e palhaço Esio Magalhães, intérprete do rato, construindo a personagem pelo seu conhecimento de teatro popular, foi incorporando ao corpo do rato as posturas corporais e movimentações de perna e braços inspiradas no rei macaco. Adicionou um rabo a um corpo corcunda e com patinhas sempre à mostra, usa sempre que possível as posturas básicas e movimentações do gong $f u$. Escolheu posturas que diminuíssem seu tamanho, como o arco negativo - onde se coloca todo o peso na perna de trás, ou a postura do escorpião, onde as pernas ficam como que enroladas. $\mathrm{E}$ assim surgiu a carismática personagem Shun Lé, nome que o rato adquire durante a peça.

\section{A Borboleta e o Dragão}

Pratico ${ }^{10}$ artes marciais desde 2000 e durante o processo assumi as funções de atriz, preparadora de gong fu e designer de movimento. Se por um lado o tempo de treino já sustentava o corpo marcial cênico, por outro, cristalizara as formas e as funções das ações e dos movimentos. O processo era o de tornar permeável, abrir espaço para a ressignificação e recriação do gong fu no dragão de fogo. Este processo foi realizado nas duas personagens estilizadas que interpreto, que não poderiam ser mais diversas em qualidade de energia, a borboleta e o dragão.

\footnotetext{
${ }^{10} \mathrm{Eu}$, Luciana Mizutani, co-autora desse artigo, tomo a liberdade de tomar a primeira pessoa, por se tratar de um trecho da criação que é um diálogo entre as funções que exerci durante o processo.

${ }^{11}$ A organização do gong $f u$ tradicional é familiar. O que traduzimos como mestre, por exemplo, vem de sifu, que quer dizer pai que transmite.

${ }^{12}$ A bandeira do espetáculo tem $2 \mathrm{~m}$ de haste e tecido com $1,40 \times 1,60 \mathrm{~m}$.
}

A borboleta surgiu da manipulação de uma das armas do gong $f u$, o leque. Embora existam armas construídas com finalidade marcial, muitas delas são ou advém de ferramentas agrárias ou objetos cotidianos. Então além de espadas, lanças e escudos existe uma variedade de armas inusitadas como tridentes de feno, flautas, bancos e leques. Objeto cotidiano antigo, em um país com muitas regiões quentes e úmidas, utilizado tanto por homens quanto por mulheres, o leque era uma arma de fácil transporte e discreta. Sem intenções ilustrativas de bater de asas, partindo de movimentos de gong $f u$, construí uma partitura de uma narradora que paira, circula observando e por vezes participa da história. Enquanto arma, a utilização do leque, tem função de bloquear a visão do oponente, para desferir ataques com outras partes do corpo, podendo também ser usado com movimentos explosivos de batidas ou de corte. Tal qual uma arma curta, versa diversas vezes em pequenos movimentos de envolvimento usando o punho. Para a borboleta, arredondei as posturas como é característica das personagens dan. Os movimentos do leque se tornaram fluídos e ampliados, sem acentos bruscos e com ênfase nas suspensões de movimento inspirando leveza e elegância.

A bandeira é normalmente utilizada em apresentações marciais carregando o brasão da escola. A despeito de não ser uma arma, muitos estilos possuem formas de bandeira, o que ressalta a ideia de performatividade ao longo da história nas artes marciais. Carregando o símbolo da família ${ }^{11}$, ela representa a escola e por isso a parte do tecido não deve tocar o chão ou ser tocada por quem a empunha. Para a personagem do dragão repensei-a como uma arma. A bandeira tem como essência tanto o direcionamento como o flamejar, podendo, sem ilustrar, criar a qualidade de uma rajada de fogo. A bandeira se tornou o dragão, ora como parte de seu corpo e ora como seu fogo, ampliando o tamanho da personagem $^{12}$. As rápidas manipulações do objeto somadas à sua grande extensão, criaram um dragão vilão, gigante e rápido frente ao menino Shun Li. 


\section{Trilha sonora, Cenário e Figurino}

A trilha sonora da peça, assinada por Marcelo Onofri, estabelece os climas das cenas. Não tem a intenção de cópia da trilha da ópera com seus instrumentos tradicionais, embora trabalhe com os mesmos princípios de linhas melódicas para momentos de lirismo e de percussões para movimentos bruscos.

A relação entre discretos cenários - apenas o necessário para a construção da fábula - e figurinos luxuosos na ópera, se manteve na concepção da peça. O cenário simples e funcional de Alan Chu e Cristina Sverzuti é uma lona clara enviesada no espaço, com um papel esquecido, onde os atores se desenham no espaço. O cenário conta com uma surpresa ao espectador, uma ponta ao fundo que se suspende formando o desenho de uma montanha no horizonte das cenas que se passam na frente da caverna do dragão.

Durante os ensaios concluiu-se que os figurinos deveriam ser construídos, desenhados e não copiados dos tradicionais da ópera. A peça contém onze personagens e apenas três atores, por isso as trocas deveriam ser rápidas. Com isso, uma palheta de cores da ópera, e a dramaturgia em mãos o estilista Fause Haten concebeu os figurinos da peça. Nas personagens humanas foram usadas cores mais sóbrias e nas personagens fantásticas cores mais fortes e vibrantes com exceção do rato onde se usou as cores do animal, cinza com rabo amarelo.

\section{$\underline{\text { O Voo do Dragão }}$}

Alçando voo no Sesc Campinas no dia 26/03/2017, a peça "O dragão de fogo" conta uma linda fábula chinesa, vibrante em cores e movimentações com inspirações e recriações da ópera chinesa. Esforço conjunto de muitos "meninos" desenhistas, o espetáculo é uma experiência estética rica, com camadas de leitura para contemplar toda a família. Uma ópera de Pequim à brasileira. $\underline{\text { Ficha Técnica do Espetáculo }}$

Dramaturgia: Cássio Pires

Encenação e iluminação: Marcelo Lazzaratto

Atuação: Eduardo Okamoto, Esio Magalhães, Luciana Mizutani

Preparação em Kung-fu e desenho de movimento: Luciana Mizutani

Música original: Marcelo Onofri

Músicos: Henrique Cantalogo (flautas, percussão marimba), Eduardo Guimarães (sanfona e percussão) e Marcelo Onofri (piano)

Captação, mixagem e masterização: Mario Porto

Cenografia: Alan Chu e Cristina Sverzuti

Figurinos: Fause Haten

Assistente de figurinos: Anna Paula Abe

Adereços: Silvana Marcondes

Fotografia: Fernando Stankuns

Programação visual: Estúdio Claraboia

Registro em vídeo: Jonathas Beck | Artma Filmes

Assessoria de imprensa: Tiago Gonçalves

Produção executiva: Mariella Siqueira

Direção de produção: Daniele Sampaio | SIM! Cultura 


\section{REFERÊNCIAS BIBLIOGRÁFICAS}

ANDRAUS, Mariana Baruco Machado. A poesia da luta: um olhar voltado para a gestualidade do estilo de gong fu louva-a-deus como estímulo para uma criação coreográfica. 2004. 203p. Tese (Mestrado) - Universidade Estadual de Campinas, Instituto de Artes, Campinas, SP.

ANDRAUS, Mariana Baruco Machado. Dança e arte marcial em diálogo: um estudo sobre o sistema de gongfu louva-a-deus e o ensino de improvisação em dança. 2012. 271p. Tese (Doutorado) - Universidade Estadual de Campinas, Instituto de Artes, Campinas, $S P$.

BERTHOLD, Margot. História Mundial do Teatro. Tradução Maria Paula V. Zurawski, J. Guinsburg, Sérgio Coelho e Clóvis Garcia. São Paulo, Editora Perspectiva, 2001.

BRECHT, Berthold. On Chinese Acting. Tradução Eric Bentley. The Tulane Drama Review, Vol. 6, No. 1 (Setembro, 1961), The MIT press. p. 130-136. Ensaio disponível em <http://sites.uci.edu/humcorebeauchamp/files/2015/09/Brecht_OnChineseActing.pdf $>$. Acesso em 08/06/2017.

CHUTE, David. Heroic Grace: The Chinese Martial Arts Film. UCLA Film and Television Archive, 2003, pg5-8. Disponível em <www.cinema.ucla.edu/sites/default/files/ HeroicGraceCatalog.pdf $>$. Acesso em 08/06/2017.

HUNT, Leo. Kung Fu Cult Masters: From Bruce Lee to Crouching Tiger. Londres, Wallflower press, 2003. ISBN 1-903364-63-9.

LEE, Ang. Crouching Tiger, Hidden Dragon. Sony Pictures Classics, Asian Union Film \& Entertainment, China Film Co-Productions Corporation, Columbia Pictures Film Production Asia, Edko Films, Good Machine International, Zoom Hunt Productions, 2000. 120min.

SOUTO, Cátia, MONTEIRO, Paula. A Ópera Chinesa em reserva: acondicionamento de trajes e seus acessórios (estudo de caso). Revista ARP. Portugal, Vol. 23. 2016. Disponível em <http://revista.arp.org.pt/pdf/2015045.pdf>. Acesso em 08/06/2017.

TARANTINO, Quentin. Kill Bill - volume 1. Miramax, 2003. $111 \mathrm{~min}$.

TARANTINO, Quentin. Kill Bill - volume 2. Miramax, 2004. 136 min.

XIAFENG, Pan. The Stagecraft of Peking Opera - From Its Origins to the Present Day. 1a ed. Beijing, New World Press, 1995. 252p. ISBN 7-80005-091-2

YIMOU, Zhang. Hero. Miramax Films. 2002. 99 min.

YIMOU, Zhang. O clã das adagas voadoras. Sony Pictures Classics. 2004. $119 \mathrm{~min}$.

WACHOWSKI BROTHERS. The Matrix. Warner Bros. Pictures, 1999. $136 \mathrm{~min}$.

WACHOWSKI BROTHERS. The Matrix Reloaded. Warner Bros. Pictures, 2003. 138 min.

WACHOWSKI BROTHERS. The Matrix Revolutions. Warner Bros. Pictures, 2003. 129 $\min$.

Sites

SIM! Cultura. <www.simcultura.art.br >

Responsável: Daniele Sampaio. Acesso em 28/06/17.

Pitágoras 500, Campinas, SP, v. 7, n. 1, p. 7-15, [12], jan./jun. 2017. 


\section{Abstract}

Reflection article on the process of re-signification of the structure and elements of composition of the Beijing opera in the play "O dragão de fogo" of Cássio Pires and directed by Marcelo Lazzaratto.

\section{KEYWORDS}

Beijing Opera; Gong fu; "O dragão de fogo" 